\title{
Perancangan Instrumen Audit Pengkodean Klinis di Rumah Sakit Umum Pusat Fatmawati
}

\author{
Kholida Syiah Nasution', Hosizah ${ }^{2}$ \\ 1,2Universitas Esa Unggul \\ Jalan Arjuna Utara No.9, Kebon Jeruk, Jakarta Barat \\ Email: ${ }^{1}$ kholidasyiahnasution@gmail.com, hozisah@esaunggul.ac.id
}

\begin{abstract}
The quality of diagnosis code is very important in the area of clinical data management, billing costs, and other matters relating to health care services. However, still often found inaccurate diagnosis codes resulting from a clinical coder. For this reason, it is necessary to conduct a clinical coding audit to improve the quality of the diagnosis code. In Indonesia some hospitals never conducted clinical coding audits because there are no instruments available for doing that. Fatmawati General Hospital never conducted a clinical coding audit . The purpose of this study is to design a clinical coding audit instrument in Fatmawati General Hospital. This is "Research \& Development" study, the Delphi technique used to validate the clinical coding audit instrument design. Subjects of this study were clinical coder experts who had at least 5 years of experience as a clinical coders and the object of this research is clinical coding audit instrument. The results of the first round Delphi technique, the seven coding quality elements of the audit instrument were approved by all clinical coder experts and used in second round questionnaires. The results of second round 2, is known that the encoding quality elements recommended for use are reliability, completeness, timeliness, accuracy, relevance, and legibility. Element definition is not used because $80 \%$ of clinical coder experts didn't recommend it. This clinical coding audit instrument needs to be considered for use in conducting clinical coding audits in health care services. However, previously this instrument need to be tested for its implementation.
\end{abstract}

Keyword: clinical coding audit, design

\begin{abstract}
Abstrak
Kualitas kode diagnosis sangat penting di bidang manajemen data klinis, penagihan biaya, dan hal lain yang berkaitan dengan asuhan pelayanan kesehatan. Sayangnya saat ini, masih sering ditemukan ketidaktepatan kode diagnosis yang dihasilkan oleh clinical coder. Untuk itu perlu dilakukan audit pengkodean klinis untuk dapat meningkatkan kualitas kode diagnosis. Beberapa Rumah Sakit di Indonesia belum pernah melakukan audit pengkodean klinis, dikarenakan belum tersedia instrumen yang dapat digunakan untuk membantu pelaksanaan audit pengkodean klinis. Salah satu rumah sakit yang belum pernah melakukan audit pengkodean klinis adalah RSUP Fatmawati. Tujuan penelitian ini merancang instrumen audit pengkodean klinis di RSUP Fatmawati. Jenis penelitian Research \& Development dengan menggunakan teknik Delphi untuk memvalidasi desain instumen audit pengkodean klinis. Subjek dari penelitian adalah Ahli clinical coder yang memiliki pengalaman minimal 5 tahun sebagai clinical coder dengan objek penelitian instrumen audit pengkodean klinis. Hasil teknik Delphi putaran 1, ketujuh elemen kualitas pengkodean dari instrumen audit disetujui oleh semua ahli clinical coder dan digunakan pada kuisioner putaran 2. Hasil dari putaran 2 diketahui bahwa elemen kualitas pengkodean yang direkomendasikan untuk digunakan yaitu reliability, completeness, timeliness, accuracy, relevancy dan legibility. Elemen definition tidak digunakan karena $60 \%$ ahli clinical coder memberikan skala 3 . Instrumen audit pengkodean klinis ini perlu dipertimbangkan untuk digunakan dalam pelaksanaan audit pengkodean klinis di fasilitas kesehatan. Namun, sebelumnya perlu diuji coba untuk pelaksanaannya.
\end{abstract}

Kata kunci : Audit pengkodean klinis, perancangan. 


\section{PENDAHULUAN}

Pengkodean klinis dapat diartikan sebagai suatu sistem pengelompokan (categories) penyakit, cedera dan kondisi kesehatan dan prosedur yang disusun sesuai kriteria yang telah ditentukan dan disepakati bersama (Pepo \& Yulia, 2015). Dalam melakukan pengkodean diagnosis kode yang dihasilkan harus akurat, complete dan konsisten. Pengkodean diagnosis yang akurat, complete dan konsisten akan menghasilkan data yang berkualitas. Ketepatan dalam pemberian kode diagnosis merupakan hal penting yang harus diperhatikan oleh tenaga perekam medis dan informasi kesehatan. Ketepatan kode diagnosis sangat penting di bidang manajemen data klinis, penagihan kembali biaya, beserta hal-hal lain yang berkaitan dengan asuhan dan pelayanan kesehatan (Hatta, 2017). Akan tetapi, masih sering ditemukan ketidaktepatan kode diagnosis yang dihasilkan oleh clinical coder.

Audit pengkodean klinis adalah proses pemeriksaan pendokumentasian rekam medis untuk memastikan bahwa proses dan hasil pengkodean diagnosis dan tindakan yang dihasilkan adalah akurat, presisi dan tepat waktu sesuai dengan aturan ketentuan kebijakan dan perundang-undangan yang berlaku. Audit pengkodean klinis perlu dilakukan untuk mereview dan menganalisis kesalahan yang ditemukan dan berusaha untuk menelusuri sumbernya, membandingkan informasi yang dihasilkan oleh clinical coder dengan informasi yang tertera di dalam rekam medis pasien, dan mengidentifikasi area praktik pengkodean yang perlu peningkatan. Proses audit dapat dilakukan dengan meninjau empat elemen kualitas pengkodean yaitu validity, reliability, completeness dan timeliness (Hatta, 2017).

Beberapa Rumah Sakit di Indonesia belum pernah melakukan audit pengkodean klinis. Salah satu penyebab hal tersebut dapat terjadi dikarenakan belum adanya instrumen yang dapat digunakan untuk membantu pelaksanaan audit pengkodean klinis. Salah satu rumah sakit yang belum pernah melakukan audit pengkodean klinis adalah RSUP Fatmawati. Berdasarkan wawancara yang peneliti lakukan dengan petugas instalasi rekam medis RSUP Fatmawati, di RSUP Fatmawati belum pernah melakukan audit pengkodean klinis. Persentase angka pending klaim BPJS di RSUP masih cukup tinggi, pada bulan Desember 2018 dari 1995 klaim diajukan terdapat $200(10,3 \%)$ klaim yang pending, bulan Januari 2019 dari 2113 klaim yang diajukan terdapat $250(11,83 \%)$ klaim yang pending, bulan Februari 2019 dari 1984 klaim yang diajukan terdapat $214(10,79 \%)$ klaim yang pending. salah satu penyebab pending klaim tersebut yaitu dikarenakan kode diagnosa yang tidak sesuai dengan ketentuan yang telah ditetapkan oleh BPJS (Badan Penyelenggara Jaminan Sosial) Kesehatan. Untuk itu, peneliti tertarik untuk merancang instrumen audit pengkodean klinis di RSUP Fatmawati. Penelitian ini bertujuan untuk merancang instrumen audit pengkodean klinis di Rumah Sakit Umum Pusat Fatmawati.

\section{METODE}

Jenis penelitian yang digunakan adalah Research \& Development $(\mathrm{R} \& \mathrm{D})$. Subjek pada penelitian ini adalah lima orang ahli clinical coder yang memiliki pengalaman minimal 5 tahun sebagai clinical coder. Objek pada penelitian ini adalah instrumen audit pengkodean klinis. Tahapan penelitian memodifikasi model pengembangan dari Sugiyono (2016) yang dilakukan sampai tahap kelima.

Tahapan penelitian dan pengembangan meliputi : 1) mengidentifikasi potensi \& masalah terkait audit pengkodean klinis, yang dilakukan antara lain melakukan telaah terhadap beberapa jurnal terkait dengaan persentase kualitas kode diagnosa yang masih rendah, dan melakukan wawancara kepada koordinator pusat data di RSUP Fatmawati terkait pelaksanaan audit pengkodean klinis di RSUP Fatmawati. 2) mengumpulkan data instrumen audit pengkodean klinis, yang dilakukan yaitu memperoleh data mengenai pengembangan instrumen dari teori pengembangan menurut Borg \& Gall (2003), Sugiyono (2016) dan teknik Delphi menurut Oka (2017). Selain itu, peneliti juga memperoleh data mengenai audit models yang dikembangkan oleh Moghaddasi, Rabiei, dan Sadeghi (2014). 3) Mendesain Instrumen Audit Pengkodean Klinis, yang dilakukan antara lain membuat desain instrumen audit pengkodean klinis berdasarkan tujuh elemen kualitas pengkodean yaitu reliability, completeness, timeliness, accuracy, relevancy, definiton dan legibility. 4) Memvalidasi Desain Instrumen Audit Pengkodean Klinis, pada tahap ini peneliti menggunakan dua (2) putaran teknik Delphi untuk memvalidasi desain instrumen audit pengkodean klinis. Validasi dilakukan oleh lima (5) orang ahli clinical coder yang memiliki pengalaman sebagai clinical coder minimal 5 tahun. 
Pada putaran 1, ahli clinical coder diminta untuk memberikan persetujuan terhadap tujuh elemen kualitas pengkodean yang meliputi reliability, completeness, timeliness, accuracy, relevancy, definiton dan legibility dan menambahkan tanggapan pada kolom yang telah disediakan. Elemen kualitas pengkodean dapat dimasuk ke Delphi putaran kedua, jika minimal $60 \%$ ahli clinical coder memilih elemen kualitas pengkodean tersebut tersebut. Pada putaran 2, kelima ahli clinical coder akan memberikan peringkat pada setiap elemen kualitas pengkodean berdasarkan skala penting 1-5 (1 : Sangat Tidak Penting, 2 : Tidak Penting, 3 : Cukup Penting, 4 : Penting, 5 : Sangat Penting). Elemen data kualitas pengkodean dianggap penting apabila didapatkan minimal $60 \%$ ahli clinical coder memilih skala 4 atau 5 untuk setiap elemen tersebut; 5) merevisi instrumen audit pengkodean klinis, melakukan perbaikan terhadap kekurangan-kekurangan yang ditemukan pada saat validasi desain instrumen audit pengkodean klinis yang telah dilakukan oleh ahli clinical coder.

\section{HASIL}

\section{Elemen-elemen dalam instrumen audit pengkodean klinis}

Instrumen audit pengkodean klinis terdiri dari tujuh (7) elemen kualitas pengkodean. Ketujuh elemen kualitas pengkodean tersebut yaitu reliability, completeness, timeliness, accuracy, relevancy, definiton dan legibility.

a. Reliability adalah konsistensi kode diagnosa dan tindakan yang dihasilkan oleh setiap clinical coder.

b. Completeness adalah kode diagnosa yang lengkap yaitu mencakup diagnosa primer, diagnosa sekunder (jika diperlukan) dan tindakan (jika ada).

c. Timeliness adalah penetapan kode diagnosa dilakukan maksimal 1 × 24 jam untuk rawat jalan dan 2 x 24 jam untuk rawat inap setelah selesai diberikan pelayanan.

d. Accuracy adalah kesesuaian diagnosa yang ditetapkan oleh dokter dan tindakan yang diberikan kepada pasien dengan kode diagnosa dan tindakan yang ditetapkan oleh clinical coder sesuai dengan ICD-10 dan ICD 9 CM.

e. Relevancy adalah kode diagnosa dan tindakan yang dihasilkan harus sesuai dan dapat digunakan untuk statistik pelaporan dan penggantian biaya. f. Definition adalah memahami semua singkatan, istilah dan simbol yang telah ditetapkan oleh rumah sakit dalam penulisan diagnosa dan tindakan.

g. Legibility adalah diagnosa dan tindakan yang tertulis dalam lembaran resume medis dan lembaran lain yang diperlukan seperti Catatan Perkembangan Pasien Terintegrasi, Patologi Anatomi dan Laporan Operasi harus dapat dibaca dan mudah dipahami.

2. Rancangan instrumen audit pengkodean klinis

Pada instrumen audit pengkodean klinis, terdapat tujuh elemen kualitas pengkodean yang terdiri dari reliability, completeness, timeliness, accuracy, definition, relevancy dan legibility. Adapun unsur yang terdapat di dalam instrumen audit pengkodean klinis untuk masing-masing elemen adalah sebagai berikut.

a. Reliability: nomor rekam medis, diagnosa / tindakan, kode yang dihasilkan clinical coder 1 , kode yang dihasilkan oleh clinical coder 2, dan keterangan.

b. Completeness : nomor rekam medis, diagnosa, kode yang dihasilkan oleh clinical coder, kode temuan auditor dan keterangan.

c. Timeliness : nomor rekam medis, Penetapan kode diagnosa dan tindakan 1 x 24 jam setelah selesai pelayanan dan keterangan.

d. Accuracy : nomor rekam medis, diagnosa dan tindakan, kode temuan clinical coder, kode temuan auditor dan keterangan.

e. Definition : nomor rekam medis, terdapat singkatan dalam penulisan diagnosa, penulisan singkatan sesuai dengan standar yang telah ditetapkan dan keterangan.

f. Relevancy : nomor rekam medis, diagnosa, pending klaim disebabkan oleh kesalahan penetapan kode, dan keterangan.

\section{Validasi desain instrumen audit pengkodean} klinis

Pada tahap validasi ini, peneliti penggunakan teknik Delphi untuk menilai apakah elemenelemen kualitas pengkodean dapat digunakan ke dalam instrumen instrumen audit pengkodean klinis. Teknik delphi yang peneliti gunakan yaitu sebanyak dua (2) putaran. Sebanyak 5 orang ahli yang berlatar belakang sebagai clinical 
coder, mengisi kuisioner mengenai elemenelemen kualitas pengkodean yang terdapat di dalam instrumen audit pengkodean klinis yang penulis buat.

\section{a. Teknik Delphi Putaran 1}

Tabel 1. Respon Ahli Clinical coder pada Rancangan Instrumen Audit Pengkodean Klinis Putaran 1 Bulan Juli 2019

\begin{tabular}{|c|c|c|c|c|c|}
\hline \multirow{2}{*}{ Elemen } & \multicolumn{2}{|c|}{ Setuju } & \multicolumn{2}{|c|}{$\begin{array}{l}\text { Tidak } \\
\text { Secuju }\end{array}$} & \multirow{2}{*}{ Keterangan } \\
\hline & $N$ & $\%$ & $N$ & $\%$ & \\
\hline ब'singilijy & 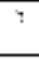 & 1.119 & a & 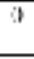 & $\begin{array}{c}\text { Devilil } \\
\text { dimusikan }\end{array}$ \\
\hline ramplerkats & 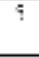 & 100 & 0 & 3 & $\begin{array}{c}\text { Draulal } \\
\text { dimpuaian }\end{array}$ \\
\hline PImoviocis & 1 & 80 & 1 & 20 & 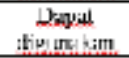 \\
\hline śniory & 1 & $w !$ & 1 & 211 & $\begin{array}{c}\text { Jaubl } \\
\text { dimusican }\end{array}$ \\
\hline Definatsoli & 5 & 100 & 0 & 9 & $\begin{array}{c}\text { Daoak } \\
\text { dimpusian }\end{array}$ \\
\hline Parivany & 5 & 100 & 0 & 0 & $\begin{array}{l}\text { Davoat } \\
\text { dimasitan }\end{array}$ \\
\hline 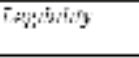 & 9 & 100 & 0 & 5 & $\begin{array}{c}\text { Droull } \\
\text { dimpuakina }\end{array}$ \\
\hline
\end{tabular}

Dari hasil teknik Delphi putaran 1 dapat disimpulkan bahwa, ketujuh elemen kualitas pengkodean tersebut dapat digunakan pada kuisioner selanjutnya untuk teknik Dephi putaran 2. Dikarenakan lebih dari $60 \%$ ahli clinical coder setuju terhadap ketujuh elemen tersebut.

\section{b. Teknik Delphi Putaran 2}

Tabel 2. Respon Ahli Clinical coder pada Rancangan Instrumen Audit Pengkodean Klinis Putaran 2 Bulan Juli 2019

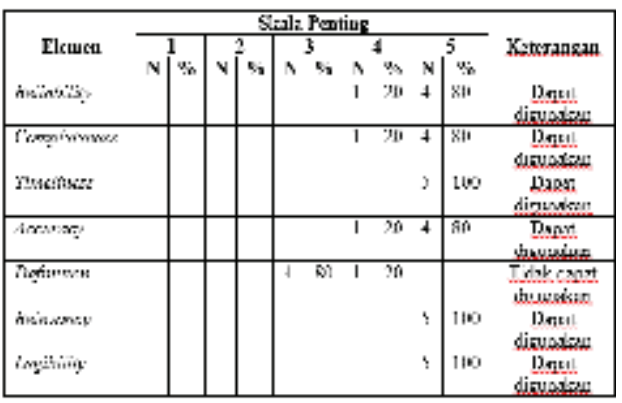

Pada tabel 2, 80\% ahli clinical coder tidak memilih elemen definition, untuk itu elemen definition tidak dapat digunakan pada instrumen audit pengkodean klinis.
4. Revisi instrumen audit pengkodean klinis

Berdasarkan hasil validasi yang dilakukan oleh ahli clinical coder dari tujuh elemen kualitas pengkodean klinis yang peneliti ajukan, hanya 6 elemen saja yang lolos dalam teknik Delphi putaran 2. Adapun elemen-elemen tersebut ialah: reliability, completeness, timeliness, accuracy, relevancy dan legibility.

\section{PEMBAHASAN}

Hasil teknik Delphi putaran 1 dan 2 diperoleh kesimpulan bahwa, dari ketujuh elemen kualitas pengkodean yang peneliti ajukan 6 elemen diantaranya dapat digunakan dalam instrumen audit pengkodean klinis. Ke enam elemen tersebut yaitu reliability, completeness, timeliness, accuracy, relevancy dan legibility. Sedangkan untuk elemen definition tidak dapat digunakan karena lebih dari 60 $\%$ ahli clinical coder memberikan skala 3 .

Hasil penelitian ini sesuai dengan penelitian yang dilakukan oleh Horsky et al (2017) dengan judul "Accuracy and Completeness of Clinical Coding Using ICD-10 for Ambulatory Visits", dalam penelitian tersebut audit pengkodean klinis dilakukan dengan menggunakan elemen accuracy dan completness. Penelitian lain yang sesuai dengan penelitian ini yaitu penelitian yang dilakukan oleh Heywood et al (2016) dengan judul "Improving accuracy of clinical coding in surgery: collaboration is key", dalam penelitian tersebut, audit pengkodean klinis dilakukan dengan menggunakan elemen accuracy.

Penelitian lain yang terkait dengan penelitian ini yaitu penelitian yang dilakukan oleh Misset et al (2008) yang berjudul "Reliability of diagnostic coding in intensive care patients", dalam penelitian tersebut audit pengkodean klinis dilakukan dengan menggunakan elemen reliability. Sedangkan pada penelitian yang dilakukan oleh Stausberg et al (2008) yang berjudul " Reliability of diagnoses coding with ICD-10", dalam penelitian tersebut audit pengkodean klinis dilakukan dengan menggunakan elemen reliability.

\section{SIMPULAN}

Setelah dilakukan proses validasi kepada ahli clinical coder dengan menggunakan dua putaran teknik Delphi, dari tujuh elemen kualitas pengkodean 
hanya 6 elemen kualitas pengkodean yang dapat digunakan dalam instrumen audit pengkodean klinis yaitu reliability, completeness, timeliness, accuracy, relevancy dan legibility.

\section{DAFTAR PUSTAKA}

Alik, A. T. N. I. (2016). Hubungan Ketepatan Kode Diagnosa Obstetric terhadap Kelancaran Klaim BPJS di RSUD Sawerigading Kota Palopo Sulawesi Selatan. Available from: https://digilib.esaunggul.ac.id/UEUUndergraduate-201434018/8006/andi-tenri

Departemen Kesehatan RI. (2006). Pedoman Penyelenggaraan dan Prosedur Rekam Medis Rumah Sakit di Indonesia Revisi II. Direktorat Jendral Bina Pelayanan Medik. Available from: https://kupdf.net/download/193973854pedoman-penyelenggaraan-rekam-medis-rs2006_58a7406d6454a78f52b1e8ee_pdf

Hatta, G. R. (2017). Pedoman Manajemen Informasi Kesehatan Di Sarana Pelayanan Kesehatan (3rd ed.). Jakarta: UI-Press.

Henderson T, Shepheard J, Sundararajan V. (2006). Quality of Diagnosis and Procedure Coding in ICD-10. Medical Care ;44(11):1011-9. Available from: https://www.researchgate. net/publication/6733229_Quality_of_ Diagnosis_and_Procedure_Coding_in_ICD10_Administrative_Data

Heywood NA, Gill MD, Charlwood N, Brindle R, Kirwan CC. (2016). Improving Accuracy of Clinical Coding Surgery: Collaboration is Key. J Surg Res. Available from: http://dx.doi. org/10.1016/j.jss.2016.05.023

Horsky J, Drucker EA, Ramelson HZ.(2017). Accuracy and Completeness of Clinical Coding Using ICD-10 for Ambulatory Visits. AMIA;912-20. Available from: https://www. ncbi.nlm.nih.gov/pmc/articles/PMC5977598/

Misset B, Nakache D, Vesin A, Darmon M, Garrouste-orgeas M, Mourvillier B, et al. (2008). Reliability of diagnostic coding in intensive care patients. Crit care;12(4):1-7. Available from: https://www.researchgate. net/publication/23134861_Reliability_ of_diagnostic_coding_in_intensive_care patients
Moghaddasi, H., Rabiei, R., \& Sadeghi, N. (2014). Improving the quality of clinical coding : a comprehensive audit model. Health Management \& Informatics, 1(2). Available from: https://www.researchgate. net/publication/310124283_Improving the_quality_of_clinical_coding_a_ comprehensive_audit_model

NHS Foundation Trust. (2013). Clinical Coding Information Governance Audit. Durham \& Darlington. Available from: https://www. cddft.nhs.uk/media/443125/07.14.05 att 1 clinical coding audit report.pdf

Oka, G. P. A. (2017). Model Konseptual Pengembangan Produk Pembelajaran Beserta Teknik Evaluasi. Yogyakarta: Deepublish.

Pepo, A. A. H., \& Yulia, N. (2015). Kelengkapan Penulisan Diagnosa Pada Resume Medis Terhadap Ketepatan Pengkodean Klinis Kasus Kebidanan. Manajemen Informasi Kesehatan Indonesia, 3(2). Available from: http://jmiki.aptirmik.or.id/index.php/jmiki/ article/view/88/72

Puspitasari, N., \& Kusumawati, D. R. (2017). Evaluasi Tingkat Ketidaktepatan Pemberian Kode Diagnosis dan Faktor Penyebab di Rumah Sakit X Jawa Timur. MANAJEMEN KESEHATAN, 3(1), 27-38. Available from: https://www.researchgate. net/publication/324252381_Evaluasi_ Tingkat Ketidaktepatan Pemberian_Kode ${ }^{-}$ Diagnosis_Dan_Faktor_Penyebab_Di Rumah_Sakit_X_Jawa_Timur

Putra, N. (2012). Research \& Development Penelitian dan Pengembangan: Suatu Pengantar. Jakarta: Rajawali Pers.

Rahayu MS. (2016). Pengembangan Instrumen Evaluasi pada Mata Kuliah Model-Model Pembelajaran Ekonomi Prodi Pendidikan Ekonomi FKIP Universitas Jambi. Available from: http://repository.fkip.unja.ac.id/search/ detil/PENGEMBANGAN INSTRUMEN EVALUASI PADA MATA KULIAH MODELMODEL PEMBELAJARAN EKONOMI PRODIENDIDIKANEKONOMI FKIPUNIVERSITAS JAMBI.html 
Rusliyanti, N. K. L., Hidayat, A. R., \& Seha, H. N. (2016). Analisis Ketepatan Pengkodean Diagnosis berdasarkan ICD-10 dengan Penerapan Karakter ke-5 pada Pasien Fraktur Rawat Jalan Semester II di RSU Mitra Paramedika Yogyakarta. Jurnal Permata Indonesia, 7(Mei), 26-34. Available from: http://www.permataindonesia.ac.id/wpcontent/uploads/2016/08/03.-Jurnal-PI_LusiAnas-Harinto.pdf

Sappaile, B. I. (2007). Konsep Instrumen Penelitian Pendidikan. Pendidikan Dan Kebudayaan, (066). Available from: http://jurnaldikbud. kemdikbud.go.id/index.php/jpnk/article/ view/356
Stausberg J, Lehmann N, Kaczmarek D, Stein M. (2006). Reliability of Diagnoses Coding with ICD-10. Med Informatics; 7:50-7. Available from: https://www.ncbi.nlm.nih. gov/pubmed/17185030

Sugiyono. (2016). Metode Penelitian Kuantitatif, Kualitatif dan $R \& D$. Bandung: ALFABETA.

Tatham, A. J. (2008). The increasing importance of clinical coding. British Journal of Hospital Medicine, 69(7). Available from: https://www. magonlinelibrary.com/doi/abs/10.12968/ hmed.2008.69.7.30409

WHO. (2010). ICD-10 (International Statistical Classification of Disease and Related Health Problems). 